\title{
Blended Interaction Spaces for Distributed Team Collaboration
}

\author{
KENTON O'HARA, Microsoft Research \\ JESPER KJELDSKOV, and JENI PAAY, Aalborg University
}

In recent years there has been an introduction of sophisticated new video conferencing technologies (e.g., HP Halo, Cisco Telepresence) that have led to enhancements in the collaborative user experience over traditional video conferencing technologies. Traditional video conferencing set-ups often distort the shared spatial properties of action and communication due to screen and camera orientation disparities and other asymmetries. These distortions affect access to the common resources used to mutually organize action and communication. By contrast, new systems, such as Halo, are physically configured to reduce these asymmetries and orientation disparities, thereby minimizing these spatial distortions. By creating appropriate shared spatial geometries, the distributed spaces become "blended" where the spatial geometries of the local space continue coherently across the distributed boundary into the remote site, providing the illusion of a single unified space. Drawing on theories of embodied action and workplace design we discuss the importance of this geometric "blending" of space for distributed collaboration and how this is achieved in systems such as Halo. We then extend these arguments to explore the concept of Blended Interaction Spaces: blended spaces in which interactive groupware is incorporated in ways spatially consistent with the physical geometries of the video-mediated set-up. We illustrate this discussion through a system called BISi that introduces interactive horizontal and vertical multipoint surfaces into a blended video-mediated collaboration space. In presenting this system, we highlight some of the particular challenges of creating these systems arising from the spatial consequences of different interaction mechanisms (e.g., direct touch or remote control) and how they affect movement and spatial configuration of people in these spaces.

Categories and Subject Descriptors: H.5.3 [Information Interfaces and Presentation]: Group and Organization Interfaces-Computer-supported cooperative work

General Terms: Human Factors

Additional Key Words and Phrases: Collaboration, telepresence, media spaces

ACM Reference Format:

O’Hara, K., Kjeldskov, J., and Paay, J. 2011. Blended interaction spaces for distributed team collaboration. ACM Trans. Comput.-Hum. Interact. 18, 1, Article 3 (April 2011), 28 pages.

DOI $=10.1145 / 1959022.1959025$ http://doi.acm.org/10.1145/1959022.1959025

\section{INTRODUCTION}

Over the last couple of decades, we have seen continual shifts in the way organizations are structured and the way that work gets done. As organizations operate more within a global environment this has created a greater imperative for work practices to operate more and more over distance. Within this climate, teams of workers are no longer assembled to just work in collocated settings. The adoption of a myriad of computermediated communication technologies has enabled teams to be assembled according

Authors' addresses: K. O'Hara (corresponding author), Microsoft Research, Cambridge, UK; email: v-keohar@microsoft.com; J. Kjeldskov, Department of Computer Science, Aalborg University, Denmark; email: jesper@cs.aau.dk; J. Paay, Department of Computer Science, Aalborg University, Denmark; email: jeni@cs.aau.dk.

Permission to make digital or hard copies of part or all of this work for personal or classroom use is granted without fee provided that copies are not made or distributed for profit or commercial advantage and that copies show this notice on the first page or initial screen of a display along with the full citation. Copyrights for components of this work owned by others than ACM must be honored. Abstracting with credit is permitted. To copy otherwise, to republish, to post on servers, to redistribute to lists, or to use any component of this work in other works requires prior specific permission and/or a fee. Permissions may be requested from Publications Dept., ACM, Inc., 2 Penn Plaza, Suite 701, New York, NY 10121-0701 USA, fax +1 (212) 869-0481, or permissions@acm.org.

(C) 2011 ACM 1073-0516/2011/04-ART3 $\$ 10.00$

DOI 10.1145/1959022.1959025 http://doi.acm.org/10.1145/1959022.1959025 


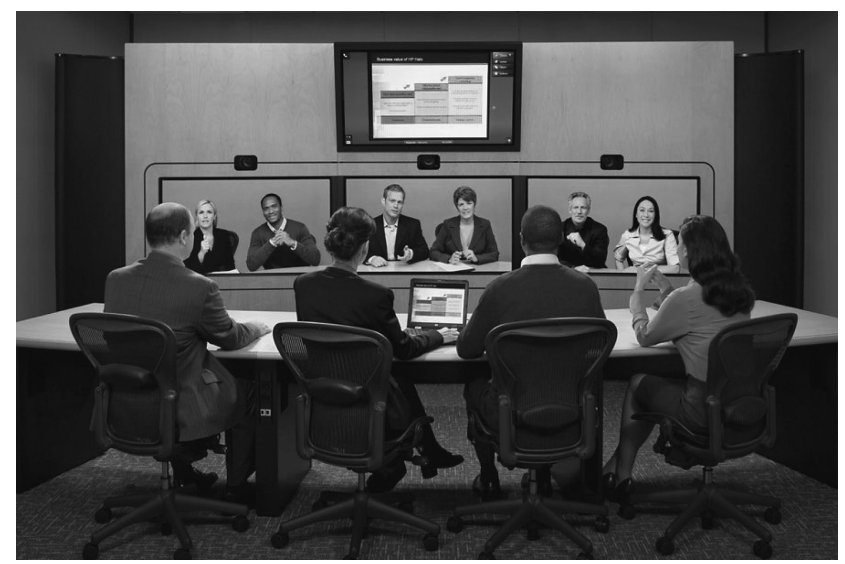

Fig. 1. HP Halo.

to the appropriate expertise required wherever it is located. The issue here is not simply about enabling a distributed set of individuals to work together which arguably are supported by a range of conventional desktop collaboration products such as video chat, NetMeeting, Google Docs, and so forth. Rather the concern is also about how to enable multiple collocated teams situated at different locations to work more effectively together when collaborating across a distance.

In spite of the progress made in collaborative technologies, the experience of distributed teamwork remains a difficult and frustrating one. Travel remains an important component in any effective operation of such teams in order to enable face-to-face interaction. Aside from significant environmental impacts, this need to travel is also costly and time consuming for the organization, creating intermittent collaboration rather than the more fluid, regular, and serendipitous interaction that characterizes collocated teamwork.

Traditional video conferencing technologies sought to overcome some of these collaborative difficulties but it is well documented that the rhetoric behind such systems never quite matched the reality of collaborative experience with such systems. There has been much research over the last 20 years that sought to understand and explain why this was the case (e.g., Buxton [2009], Dourish et al. [1996], Finn et al. [1997], Gaver et al. [1993], Harrison [2009], Heath and Luff [1991, 1992], Hirsh etal. [2005], Mantei et al. [1991], Nguyen and Canny [2005], Noll [1992], O'Connaill et al. [1993], Olson et al. [1997], Olson and Olson [2000], Sellen, [1992, 1995], Sellen et al. [1992], Sellen and Harper [1997], Short et al. [1976], and Tang and Isaacs [1993]). As such, while these systems support some limited communication activities within distributed teams, they often remain underutilized for collaborative activities of any realistic complexity. A recent study conducted in one particular organization has indicated that traditional video conferencing systems are used on average for only 12 hours per month [Weinstein 2005]. This level of usage matches well with the research findings in the literature relating to user experience and organizational factors that often hinder use.

In recent years though, we have seen the introduction of more sophisticated video conferencing technologies that have led to a stepwise increase in the collaborative experience between remote team members. Systems such as HP Halo (see Figure 1), Cisco Telepresence, Tandberg T3, and Polycom TPX provide an enhanced user experience, with research showing usage rates of such systems as much as ten times higher than traditional video conference systems [Weinstein 2005]. Our intention here is not 
to overplay the significance of these comparative statistics, as there are a number of factors underpinning them. For example, the fact there are more of the traditional video conferencing units relative to the higher-end systems is a contributing factor. But in part they are also attributable to the enhanced user experience associated with these higher-end systems with users saying the technology "disappears" enabling them to focus on the collaboration [Gorzynski et al. 2009; Weinstein 2005]. The experience and usage rates with these high-end systems, then, appear to challenge some of the well-established difficulties with traditional video conferencing systems.

Articulating the reasons for why these systems challenge some of our assumptions about the value of video-mediated communication is one of the concerns of this article. While there are a number of possibilities for how we may approach this, the way we aim to do so in this article is through a closer look at the design characteristics of these systems using the Halo environment as an example, drawing on and extending the work of Gorzynski et al. [2009]. Our concerns here are more than simply a characterization and explanation of the Halo system design. Rather, we want to use this characterization to exemplify the broader design philosophy behind such systems. In particular, we want to articulate further what Gorzynski et al. have come to call "Blended Spaces," that is, distributed set-ups in which the design of the whole environment produces a geometrically coherent representation of the remote site, faithfully representing its spatial geometries with respect to the local site. This provides the perception of unified spatial frame of reference for all parties.

Taking this as a starting point, we want to argue how the basic blended space philosophy can be extended to think about an ecology of other distributed workplace environments that support a broader variety of distributed collaborative work practices. In particular, one of the key aims of the article is to extend the Blended Spaces work to see how collaborative practices can further be supported by the introduction of interactive information workspace elements into such environments. That is, we will move towards what we have come to call "Blended Interaction Spaces." Our concerns here are to illustrate some of the design challenges of making such a move and the ways that different interaction mechanisms and approaches can affect the way that we achieve geometrically coherent representation of the remote site with respect to the local site. As with the characterization of the Halo system we will adopt a similar approach of articulating the characteristics of Blended Interaction Spaces through a system we have developed for data-intensive collaboration for distributed small groups.

Before we delve into a deeper articulation of Blended Spaces and Blended Interaction Spaces, we want to first take a step back and set some context within which to ground some of the subsequent discussion. We discuss first of all notions of embodied action and the importance of physical space as the basis for coordinated action, meaning making, and intersubjective understanding. We see how the notion of embodied action is used to make sense of the communication and collaboration behaviors arising in media spaces and traditional video-mediated communication and through this set the scene for understanding some of the design directions of Blended Spaces. Building on the ideas of how action is enacted embodied in space, we move on to a discussion of the ways that our social action and behavior are influenced by our spatial configuration with respect to others and objects. This discussion draws in particular on Hall's [1966] notions of proxemics and Kendon's theory of $F$-formations of interactional space. We go on then to discuss workplace design where again, notions of physical space are fundamental. Like

\footnotetext{
${ }^{1}$ While the work of Gorzynski et al. [2009] articulates characteristics of blended spaces, they do not actually make explicit reference to the term in this article. The term, though, is attributable to Gorzynski and his Halo colleagues but one that has been shared with the current authors through personal communication while working with the Halo team at HP.
} 
CSCW, workplace design has as one of its central concerns the way effective workplace collaboration is achieved. In contrast to much of CSCW, workplace design approaches this from the point of view of designing physical space, from architectural elements through to specifics of furniture design. We then articulate where CSCW and media space research have drawn on notions of spatiality in the design of distributed environments. This leads on to our discussion of Blended Spaces and Blended Interaction Spaces.

\section{EMBODIED ACTION AND MEDIA SPACES}

One of the key ways that CSCW has concerned itself with notions of space is through the notions of embodied action (e.g., Dourish [2001] and Robertson [1997]). Drawing on the philosophical foundations of phenomenologist thinkers such as Husserl, Heidegger, and Merleau-Ponty, these authors take as their starting point that consciousness and perception are active, interpretive, and embodied, arising from our presence and action in the world. It is through our actions that we are able to create shared meanings with other people. Robertson [1997] argues that of particular importance is Merleau-Ponty's notion of reversibility [Merleau-Ponty 1962, 1968]. Quoting Robertson [1997]:

\footnotetext{
"Reversibility is the complex, reciprocal insertion and intertwining of the sensed and the sensing, that is the essential condition of our interaction with the world and with others. In a shared physical space a lived body can simultaneously see and be seen, touch and be touched, make sounds and be heard, move and reorient its perspective and cross over these sensory modes; that is, see both itself and others being touched or touching, moving, making sounds, etc. The fact that we are able to perceive our own bodily surfaces at the same time as we live our acting bodies enables us to organise our actions. The public availability of these actions to the perceptions of others enables them to organise their own actions in relation to ours."
}

The key issue here is that coordinated action, meaning making, and intersubjective understanding are shaped, in part, from our embodied actions in space and the availability of these actions to others and the availability of others' actions to ourselves, for example, the way we move, point, touch, and gesture in relation to objects and other people in that physical space. Thinking about coordinated action and meaning in this way was an important foundation for much of the early analytic enquiries into media spaces and video-mediated communication. In particular, of interest were the ways video-mediated communication distorted some of the essential shared spatial properties of action and communication in the form of various asymmetries [Dourish 2001; Gaver et al. 1993; Heath and Luff 1992, 2000]. These asymmetries have been argued to stem from orientation disparities arising from particular camera and screen configurations and affect access to the common resources used to mutually organize action and communication. As Heath and Luff [2000] articulate:

\footnotetext{
"... gesture and other forms of bodily activity are systematically designed with respect to the local environment and the emergent conduct within the interaction. In video co-presence, mediated through audio-visual technology, the camera and the monitor inevitably delimit and distort your access to the co-participants. Your view of the other is from a particular angle and severely circumscribes access not only to the other and their bodily conduct but to the local environment in which it is produced. In consequence your ability to design a bodily movement such as a gesture which is sensitive to orientation to the other and their relationship to their own environment is problematic. Moreover, the limited access to the other also means that you are relatively unaware of changes within their local environment with which your visual conduct may well be competing; for example, changes to the content of their computer screen or their workstation, or even people entering the room... The technology therefore provides physically distributed individuals with incongruent environments for interaction. What I see is not what you see, and I am unable to see how you see me and the actions in which I engage. Despite this incongruity, individuals presuppose the effectiveness of their conduct and assume that their frame of reference is 'parallel' with their co-participant's. They presuppose, for the practicalities at hand and their
} 
mutually coordinated activity, that their image of the other is congruent with the image of them... This presupposition of a common frame of reference, a reciprocity of perspectives, is a foundation of socially organized conduct." [Heath and Luff, 2000, p. 198]

Within traditional video-mediated communication the lack of common spatial reference points with which coordinated action and meaning can be facilitated resulted in welldocumented difficulties with certain tasks in these environments, or the need to adapt behavioral practices within these new spatial contexts. Pointing to objects, looking at objects, orienting towards other people within these video-mediated spaces were all things that needed to be consciously reinterpreted rather than being "natural" forms of interaction.

\section{SPATIALITY AND HUMAN INTERACTION}

As well as the argument that action is embodied and enacted in physical space, it is important too to understand the ways that our social action and behavior are influenced by our spatial configuration with respect to others and objects. These understandings provide important foundations for the blended space arguments, but are informative too when thinking in more detail about the specifics of their design. A key contribution to this issue can be found in the work of Ed Hall and his notion of proxemics [Hall 1966]: man's use of space as a specialized elaboration of culture. One of the key themes within Hall's work concerns the notion of physical distances that people maintain between each other according to their relationship and type of interaction. He characterizes four main spatial distances that exist around a person: intimate distance, personal distance, social distance, and public distance. Intimate distance is somewhere in the range of 0 to $45 \mathrm{~cm}$ and is reserved to interactions with lovers, family, and close friends. Personal distance is in the range of $45 \mathrm{~cm}$ to $1.2 \mathrm{~m}$ and is the distance that we naturally would maintain from strangers in everyday life. Social distance is between $1.2 \mathrm{~m}$ and $3.6 \mathrm{~m}$, getting gradually more formal towards the further end of the scale. Hall argues that it is in the social range that work and business meetings typically occur. The public distance is anything beyond $1.2 \mathrm{~m}$ where one loses any sense of personal involvement with the other actor, for example, a person giving a speech in a conference hall. These zones then are of significance for how we conduct interaction and can lead to psychological discomfort if they are broken. This is not simply arbitrary but in part relates to the opportunities for certain types of actions that are possible in these different spaces. For example, what can be seen and taken in with a visual sweep of a certain angle is dependent upon the distance from the subject. This, in turn, affects the patterns of gaze and eye movements that are made and interpreted as acceptable at particular distances. Hall also discusses how height differences in these zones can subtly alter the nature of the interaction and interpersonal relationships. Consequently, to stand and look down at someone in the social zone can confer a particular advantage over the person sitting. While the interpersonal distances are the most familiar aspects of Halls' work, his arguments are much broader and concern more general ways in which human interaction is spatially organized. Indeed, his discussion highlights the significance of different spatial configurations of interacting parties in relation to communication characteristics. For example, sitting next to someone at a table versus sitting across the table from him can influence the communication dynamics between dyads.

An understanding of these different spatial configurations of interacting parties is developed further in the seminal work of Kendon [1990], in particular in his articulation of the $F$-formation, which is essentially the "spatial and orientational organization of participants." The transactional segments (the area in front of each body) overlap to form the o-space, the shared interactional space to which the participants have mutual access. Participants continually arrange themselves throughout an interaction in 
a way that maintains the mutual access to the space. There are a number of points of significance that relate to the spatial organization of interaction. The first is that different f-formations alter the nature of conversation and interaction. Even different positions within particular f-formations can also have an impact on the conversational relationship between different parties (e.g., Sommer and Ross [1958], Sommer [1969], and Steinzor [1950]). Second, studies show that gestures (including body orientation and gaze) are very much impacted by and dependent upon the spatial arrangement of bodies in the formation (e.g., Ozyurek [2000, 2002]). Healey and Battersby [2009], for example, argue that the mutually known arrangement of participants, gestures, and orientation are used to create what they call interactional maps of conversational contributions. These interactional geometries support a number of things such as references to locations as representative of prior turns, as representative of the turns' producers, and as ways of keeping subdialogs visually distinct from one another. In this respect, physical reference space is used not just to gesture to actual objects and artefacts in the shared space but is also used to organize gestural reference to more abstract concepts, for example, "earlier" or "later" might be represented in spatial terms such as left and right.

Spatial features of the world and the way things are organized are also laden with social meaning and protocols that people make use of in their everyday life to interpret what is going on and how to behave [Buxton 2009]. For example, as Buxton suggests, sitting at the head of the table confers an understood social status that can be understood; or two people walking in the park can be interpreted as friends or lovers depending on their observed interpersonal distances mentioned earlier. These space-function-distance relationships are important to reflect upon in design.

\section{PHYSICAL WORKPLACE DESIGN}

While CSCW has as its core focus the impact of technology design on collaborative work practices, other fields of research and design have oriented more closely to the relationship between spatiality and human interaction and the impact of space-functiondistance design on effective collaborative practices (e.g., Becker and Steele [1995], Duffy [1997], Laing et al. [1998], and Steelcase360 [2007]). Authors such as these and others in the workplace design and facilities management literatures essentially argue that the design of different physical spaces affects the social and informational aspects of an organization and its work practices. Different physical spaces are designed to support a range of different individual and collaborative work practices and the fluid movement between these [Laing et al. 1998]. These spaces are characterized by different architectural dimensions, wall sizes, lighting, furniture configurations, and information artefacts and technologies. Room dimensions, for example, affect the size of groups that can be accommodated in collaborative settings. Wall and boundary design can affect the openness, visibility, and audibility of a space with respect to the larger office environment [Laing et al. 1998]. The design of table shapes can be used to affect proxemic arrangements such as interpersonal distance between collaborating parties and also the f-formations that people construct in relation to each other and information artefacts in the room. Table heights can be used to cause people to sit or stand. Different seating arrangements can be used to create different postures and orientations to people and information artefacts in a space. The point here is that different spaces are composed of particular configurations of architecture, furniture, and technology, the interacting dimensions of which profoundly affect the social, informational, and collaborative practices that can take place within them along the lines of the arguments made by Hall [1966] and Kendon [1990]. The point too is that these spatial dimensions can and are deliberately designed with particular social effects in mind. 


\section{BLENDED SPACES: THE EXAMPLE OF HALO}

The considerations for physical space design and the impact on collaborative practices are the starting point for understanding the design choices in Halo and their contribution to the user experience. In designing the system, the Halo team focused on four aspects of the user experience: work (what kind of work will take place in that space and what tools are needed), communication (what dynamic verbal and nonverbal elements are required), interaction ${ }^{2}$ (control of the set-up and work tools), and service (support services for maintenance, optimization, and troubleshooting) [Gorzynski et al. 2009]. With this in mind, the team started first with a look at what typical traditional video conferencing set-ups would be if considered in terms of equivalent physical spaces. What the team concluded was that with traditional videoconference set-ups screens and cameras are positioned in ways that are primarily appropriate for local participants or placed simply due to installation pragmatics. Often, then, they are placed out of the way where televisions or media screens would be placed. Considering this in terms of a meeting happening in physical space, the Halo team argued this was equivalent to seating some meeting participants in the corner of the room away from the main table (refer to Buxton [2009]). This creates lots of well-documented problems and presence disparities in terms of participants not being included in the meeting or being forced to watch the meeting from a corner rather than be actively involved. With this in mind, the starting point for Halo design was to think of what would be the appropriate configuration of collocated physical space design if it were to effectively support collaboration of a particular type and size. The next step would then be how to transform the physical dimensions and characteristics of the ideal physical room and recreate these properties perceptually in a distributed setting through a carefully crafted configuration of architecture, furniture, and technology elements. This would include manipulating things such as camera positioning, display arrangement, wall design, table design, lighting, and audio design to create geometrically correct representations of the remote site; to provide in essence the visual sensation of remote parties sitting in the same ideally designed physical environment. This is what Gorzynski et al. [2009] refer to as the spaces becoming "blended"; that is where spatial geometries are preserved across the distributed settings providing a unified perceptual frame of reference that facilitates interpretation of embodied actions.

Within this basic philosophy, it would have been possible to develop a range of different Blended Space environments that broadly map onto the ecology of different collaboration environments we see in the physical workspace as previously outlined. As the first development, though, the initial Halo studio chose a base physical work setting where the design was oriented to a small boardroom-type environment that would accommodate meeting sizes of up to 12 people. The type of work being supported here was relatively small meetings for critical business discussion where the focus of the meeting is conversation and where the group nonverbal communication aspects are too important for a voice-only conference call [Gorzynski et al. 2009].

The base physical space was chiefly based around a table designed to position six people either side of an elliptical table. This base design would position people at a physical distance and orientation from each other appropriate for a meeting of this type. In Hall's [1966] terms, this kind of work takes place within the range of social distance:

\footnotetext{
${ }^{2}$ As with the Gorzynski et al. framework, we share some concerns with the interactive tools. The focus of our arguments in this article extend the discussion of these beyond just thinking about what tools are needed for a particular type of work. Critical to our arguments here is that the tools and particular interaction mechanisms are an integral part of the communication experience, changing assumptions we can make with respect to proxemic configurations of people, the collaboration dynamics, and the fundamental nature of their expressive possibilities.
} 
somewhere between $1.2 \mathrm{~m}$ and $3.6 \mathrm{~m}$. Starting from this base physical space concept, the design of the Halo system then sought to recreate these physical dimensions of this space across the distributed setting [Gorzynski et al. 2009]. In doing this, the design was guided by a number of key principles: magnification constancy of images from multiple sites; correct eye heights; consistent foreground and table height across sites; perspective distortion reduction; alignment of $\mathrm{AV}$ components for correct eye contact and gesture awareness; and representation of spatial audio. This involved management of the interacting factors of room geometry, lighting, furniture, screen size and position, and camera arrangement.

In each Halo room, there is a panoramic array of three displays on the front wall. The width of the three-display arrangement matches the width of the table. The screens are placed at the appropriate physical height with respect to seated participants, so that the eye levels of the local and remote participants are at the same height as if the remote participants were sitting on the opposite side of the table. With cameras directly above the screens at this height and physical distance, vertical eye gaze contact error is also mimimized [Gorzynski et al. 2009]. With regards to the data screen provided in the Halo rooms, positioning of the display was also a key consideration for Gorzynski et al. Their argument was that placing the display above the participants kept it close to the participants, making it easy to see both information and participants at the same time without distracting focus from the conversational and nonverbal communication elements.

The table placement is such that it positions the participants at the appropriate physical distance from the screens. This combined with the correct camera zoom creates the necessary size representation of the remote participants that creates the perception of the desired physical distance between participants set out in the base physical space boardroom design. The three cameras are calibrated to provide a consistent zoom level such that they can be combined into a single consistent panoramic view across the three screens. Likewise, color and balance are fixed rather than automatically adjusting, and consistent across the cameras, again to facilitate the perception of a single panoramic image. The representations of the remote site show upper body and head views at the correct size. This is consistent with the recent findings by Nguyen and Canny [2009] that demonstrate how such framing can facilitate the development of trust across the distributed settings relative to, for example, head-only views.

Other aspects of the table design are also crucial. For example, the curvature of the table helps align people with the three camera views so that they are facing in a direction that helps the perception of eye gaze. ${ }^{3}$ Table legs are strategically positioned so that pairs of participants sit between them. These positions correspond again to the camera views and in doing this people naturally sit so that they appear on a single screen. Likewise there are subtle joins on the table that also provide cues to seating position. What is important about the design here is that the constraints and cues are embodied in the environment. As such, position can be implicitly oriented to without the need for conscious consideration. We can draw some theoretical parallels here with early work in cognitive psychology and HCI (e.g., Larkin [1989] and Zhang and Norman [1994]) and more recently with advocates of embodied interaction (e.g., Dourish [2001] and Hornecker and Buur [2006]) that discuss the important ways that physical constraints on action can be embodied in the environment. Because these cues help position people appropriately, this contributes to Halo's design working without

\footnotetext{
${ }^{3}$ Eye gaze in Halo is never going to be perfect as the same image is presented to participants regardless of where they sit. But there are emerging solutions to this problem in which different images can be presented to participants according to where they sit, greatly enhancing the possibilities for accurate eye gaze throughout the environment. For example see Nguyen and Canny's [2005] MultiView technology.
} 
the need to provide visual feedback to the participants about how they appear on camera. This is a significant design consideration in the sense that it promotes greater transparency of the technology and the illusion of a unified space since no picture-inpicture arrangement is present to break the illusion.

The table size and positioning with respect to the cameras plays a further role in providing continuity across the distributed space. The set-up of these elements is such that a small proportion of the table is made visible on the displayed representation of the remote site. The table edge then provides a continuous line across the panorama of screens and gives the impression of completing the table in the local space. As such, the perception is of the participants being sat on the opposite side of the table. Achieving this effect is actually a more involved configuration than might first appear. Because of the camera placement above the screens and its physical distance from the seated participants, there are inevitably perspective distortions introduced into the image. If too much of the table edge is shown in the displayed image, then these camera distortions are more salient in the image in a way that is damaging to the illusion. There is a necessary balance between showing just enough of the table to represent the continuity across the spaces but not enough to reveal inherent camera distortions. This again is achieved through the careful design and arrangement of the technology and furniture elements.

These potential distortions in the image arising from the camera placement have a relationship with the design of the architectural elements of the rooms, namely the walls. The walls are designed to be as neutral as possible. No decorative detail is included. The camera angles and focal length are such that horizontal and vertical lines are not present in the represented image on the displays. For example the joins between the walls and the ceiling, or the walls and the floor, are deliberately not visible in the image. Traditional video conferencing shows no real concern for such details. But the point here is that such horizontal and vertical lines again make the camera distortions much more salient, appearing curved. By carefully combining architectural detail appropriately with camera views, these effects can be minimized.

As with film and photographic studios, lighting was also an important consideration with side and overhead lighting carefully chosen to illuminate participants naturally without introducing shadows and too many depth cues. These lighting choices interacted with other architecture, furniture, and technology elements in the space. For example, with the front wall housing the monitors, the lighting of this wall had to be dimmer to avoid glare on the monitors. Within this arrangement, the front walls appeared darker than the rear walls and consequently did not match the color of the image appearing on the screens. This made the screens feel discontinuous from the front wall. In order to compensate for this and achieve a consistent color across the front wall and wall color as represented on the screen, slightly lighter-colored wall panels from the rest of the room were chosen. Again we see here a solution based on a combination of the architectural with the technical.

Other aspects of the Halo design are also kept constant in an attempt to maintain the transparency of the room. A good example here is the full duplex audio that is kept at a constant volume. There is no interface control presented to the user to allow adjustment of such features of the environment. From one perspective, this may be seen as inflexible and a limitation in terms of the level of control afforded the user. But actually, such design decisions represent an important part of the blended space design philosophy, namely that the space be as immediate to use as walking into a normal physical meeting room. Removing layers of control is part of creating this feeling. So for example, if in a normal physical space there are difficulties hearing, one simply requests that a person speak up. So too are such protocols an inherent part of what is trying to be achieved in Blended Spaces such as Halo. That 
is, these things are dealt with through social mediation rather than technological manipulation.

Finally, of importance to the Halo design is the whole notion of symmetry. Each and every Halo room is identical in its configuration of architectural furniture and technology elements. In the distributed set-up, each Halo room acts as the completing half of the other room, to maintain the perception of the single continuous physical space. Using symmetry in this way obviously brings its limitations in terms of flexibility of the system, for example, in terms of the openness and number of sites that can be connected to relative to technologies such as Access Grid. The intention here though is not to cover all value points in the arena of video conferencing since these lead to particular compromises and trade-offs in the design. The intention rather is to take a certain type and size of collaboration and create an environment that works well for this, as opposed to designing a more flexible system that compromises the experience. There is no right and wrong answer here in design terms, but simply one of focusing on different value propositions. Symmetry is also helpful in maintaining a geometrical coherence necessary for supporting the correct spatial representations of gestures and attention direction. As Heath and Luff [1991, 1992, 2000], Gaver et al. [1993], and others have argued, asymmetries in media space arrangements can lead to difficulties with the lack of common frame of reference necessary for effective communication. Within the conceptual framework of embodied interaction [Dourish 2001; Robertson 1997] these symmetrical arrangements better facilitate achievement of intersubjective understanding of action. It is this intersubjective understanding of action that allows Halo to dispense with the picture-in-picture model of video conferencing showing an image of the local participants; symmetry and its accurate spatial representation facilitate an embodied understanding of how others appear and how one appears to others.

\section{BLENDED INTERACTION SPACES}

As has been discussed, the current Halo system and other similar commercial Blended Space offerings are designed specifically to support a certain type of collaborative work, in particular, critical business discussion with a focus on conversation and group nonverbal cues. The document and information sharing tools needed for this kind of collaboration are fairly minimal which is reflected in the design choices within the current Blended Spaces. For example, in Halo, there is a VGA out solution from a connecting laptop to the fourth display above the three panoramic displays. This realistically only allows single documents to be viewed at any one time. Any interaction with the information on this display is restricted to one person in front of the laptop. This use of a single document where control is maintained with the presenter is appropriate for the kind of collaborative work being supported by Halo.

What happens, though, when we consider collaborative work in which there is more complex, data-intensive collaboration around documents (e.g., scientific analysis, emergency response, military planning)? Research has shown how shared document and information spaces provide an important resource in scaffolding collaborative talk and work, playing a number of different roles. For example, they are something that can be pointed at and worked on during conversation allowing the use of more efficient deictic language (e.g., Bly [1988], Bly and Minneman [1990], Heath and Luff [1991], Luff et al. [1992], Sellen and Harper [2000], Spinelli and O'Hara [2001], and Whittaker [2003]). They can provide an ongoing history of a meeting as they are manipulated. These representations embody the knowledge and decisions created through the collaborative work. The process of seeing things being added to the shared surface creates a sense of commitment and ownership to the ideas and information that is important during evaluative phases and assignment of action (e.g., Moran et al. [1999], Spinelli [2003], 
and Whittaker and Schwartz [1995]). Providing persistent representations of information is also important for ongoing referral throughout meetings. People need to draw those visual resources into conversations that are immediately to hand (e.g., Sellen and Harper [2000]). If there is effort necessary to bring in a shared visual reference and interact with it then it is much less likely to take place [Perry et al. 2001; Spinelli et al. 2005; Spinelli and O'Hara, 2001]. In these more document-intensive collaboration tasks, large amounts of information and data from different sources need to be viewed and interacted with concurrently in order to facilitate the cognitive demands and social dynamics of the collaboration. In physically collocated situations, the ability to assemble a collage of information artefacts is easier: information resources such as documents can be arranged adjacent to each other and navigation back and forth between the different information sources is simpler and more tangible; information can also be spatially arranged to facilitate the cognitive processes of information synthesis (e.g., Kirsh [1995], Hutchins [1995], Rogers and Bellotti [1997], and Spinelli et al. [2005]).

But the issues are not only about supporting the information processing in these tasks. As a collaborative activity, the information artefact-centric interactions, gestures, and manipulations are a fundamental component in the conduct of communication within Kendon's $O$-space [1990]. The embodied nature of actions in relation to a commonly understood spatial frame of reference is particularly significant for these kinds of data-intensive tasks and the coordination of talk and activity that occurs around the artefact space. Again, in physically collocated situations, the artefact space provides the shared spatial references that provide the foundations of intersubjectively produced and interpreted actions and talk. With distributed collaboration there are no simple solutions for providing this in any rich way and certainly not within the existing high-end commercial Blended Space systems such as Halo. Providing such support in distributed settings is key for this kind of collaborative work. Doing so in a spatially faithful way across distributed settings is even more important for this kind of work activity than in the social business communication work supported by Halo, because of the richer coupling of talk to embodied action.

Another key component of these data- and information-intensive collaborative activities is the use of multiple entry points in to the task, whereby different team members have equal opportunities to simultaneously access and interact with the information as the needs of the collaboration dictate [Rogers et al. 2009]. Collocated ecologies of physical information artefacts provide multiple entry points, offering this scope for multiple people to interact with information from different sources at the same time. This is not simply significant because it allows people to organize this collaborative work in different ways (e.g., working on part of a task together or on different parts of the task in parallel); it is also significant for how people can choreograph their talk with reference to information artefacts. Imagine if you have to put your hand up every time you want to talk in a group setting. This would rapidly become burdensome and ultimately affect the fluidity with which group discussion could take place; the same is true for single entry point interaction mechanisms. The dynamics and impact of multipoint interaction mechanisms on more data-intensive collaborative activity are now beginning to be demonstrated and explored in collocated settings (e.g., Hornecker et al. [2008], Jiang et al. [2008], Nacenta et al. [2007], Rogers and Lindley [2004], Rogers et al. [2009], and Wigor et al. [2009]). This ability for all team members to concurrently interact with multiple pieces of information from disparate sources is not well supported in distributed settings beyond bespoke application-level implementations, and certainly not supported in the current commercial high-end Blended Space systems.

In thinking about how to extend Blended Spaces to become Blended Interaction Spaces, there have been a number of significant advances in recent years that open up 
opportunities for a more effective type of this data-intensive collaboration between distributed teams. Large, high-definition data panels, multitouch-sensitive horizontal and vertical surfaces, multiperson input capabilities, and multidisplay environments and techniques for viewing data from multiple sources offer intriguing new ways for collaborative teams to simultaneously view and concurrently interact with large amounts of data. A large number of research projects have investigated many aspects of these new possibilities for collocated settings, some notable examples being i-land [Streitz et al. 1997; 1999] Stanford iRoom [Johanson et al. 2002], and more recently WeSpace [Jiang et al. 2008; Wigor et al. 2009] to name but a few. Such systems though focus primarily on collocated collaborative settings.

Research on these kinds of systems and technologies has shown how different configurations of interactive surfaces have particular properties with regards to how information can come to be shared and used within collaborative contexts (e.g., Huang et al. [2006], Russell and Sue [2003], and Trimble et al. [2003]). Particular form factors and size of displays, horizontal and vertical orientations, and the ways they are configured with respect to other artefacts and architectural elements within a collaborative work setting, as well as a range of different interaction mechanisms (touch versus remote interaction) all have a significant impact on the way that people spatially arrange themselves with respect to the information and with respect to other members of the group. This in turn shapes the social dynamics of collaborative activity impacting on, for example, things such as control structures within the group. For a group to simultaneously interact around a large vertical touch screen, for example, requires people to arrange themselves in a line adjacent to the surface. With horizontal surfaces people sit or stand around a tabletop and interact with the information from a variety of orientations according to the size, shape, and height of the table. Rotation mechanisms for objects on these horizontal surfaces and the ability for multiple people to interact at the same time mean that the people gathered round the table can interact with the information from wherever they are sitting or standing (e.g., Hornecker et al. [2008], Nacenta et al. [2007], Rogers and Lindley [2004], and Rogers et al. [2009]).

The argument we want to make here is that there are proxemic consequences of these interactive surfaces and mechanisms: what we call interaction proxemics. These interaction proxemics create particular considerations when trying to introduce them into a Blended Space environment. As we discussed in the previous section, Halo and other Blended Spaces are carefully crafted in terms of architectural, furniture, and technology dimensions and arrangement to introduce necessary spatial constraints and cues that lead to geometrically coherent representations of distributed spaces. This allows assumptions to be made about how people will arrange themselves that enables appropriate camera and display configuration. Given the proxemic consequences of different interactive surfaces and mechanisms, the introduction of such systems into a Blended Space needs to be done in the same carefully crafted manner. As a simple illustrative example, if one were to introduce a large vertical touch-sensitive surface into a Halo-type environment the interactional properties of the surface will encourage people to stand up and interact with it leading people away from the carefully positioned camera and display arrangement.

The arguments here in relation to the interaction proxemics are twofold. On the one hand, it is important to understand how the physical configuration of the environment and information artefacts can be designed to accommodate the particular spatial dynamics introduced by these different interaction mechanisms. On another hand, it is important to consider how other elements in any particular Blended Space configuration (e.g., video and data display arrangement, camera positioning, microphone and speaker positioning) impact on the ways particular interaction mechanisms are subsequently used because of potentially competing spatial requirements. For example, 
if we take the same simple interactive whiteboard example as illustration, would the need to be positioned in the line of sight of the camera and in the vicinity of microphone set-up in a Blended Space actually prevent people getting up to use the whiteboard? The design of a Blended Interaction Space, then, needs to consider these interacting factors.

In order to unpack this further, we follow the approach adopted in the Blended Space argument in which Halo was used as an illustrative exemplar to highlight key issues of Blended Spaces with reference to particular design features. In our extension of this discussion to Blended Interaction Spaces, we use as an illustrative example a system called BISi (see Broughton et al. [2009]), a blended interaction space developed for small group data-intensive collaboration. It is important to recognize this system as just one example in a much larger design space of blended interaction spaces for different types of collaborative work. The purpose of our discussion using this example is to highlight issues, challenges, and considerations arising from attending to interaction proxemics in the creation of geometrically coherent distributed collaboration tools.

\section{BISI: BLENDED INTERACTION SPACE FOR SMALL GROUP DATA-INTENSIVE COLLABORATION}

Just as Halo had taken as its starting point a boardroom-type physical space for supporting meetings of up to 12 people, the base physical starting point for the BISi systems was aimed at supporting smaller group collaborations between of two or more people and no more than eight. In addition, BISi was designed to support more data-intensive collaboration around multiple data sources and documents. In assembling a Blended Interaction Space of this type, the concerns needed to be with the provision of a shared digital workspace across the sites as well as with the geometric configuration of the physical set-up. In presenting this discussion then, we begin with a brief overview of the shared digital workspace application, TAPESTRY. The intention here is not to engage in a detailed technical specification of the system (which will be the subject of other research papers) but rather a sufficient overview of the functional characteristics that are necessary for a discussion of the interaction proxemics associated with the BISi system. That is, particular features of TAPESTRY have implications for the spatial consequences of interacting with the system that relate to how blending may be achieved. And it is these that we wish to discuss in relation to the design of BISi. Following the description of TAPESTRY, we will discuss the set-up of BISi and the ways in which the configuration of architecture, furniture, and technology elements create geometrically correct representations of the remote site in light of the new interactive properties.

\subsection{TAPESTRY}

TAPESTRY is a distributed application framework shared across remote sites designed to provide a common interactive workspace. It can be considered as a conceptual "surface" shared by all sites onto which local and remote participants can share "windows" and "applications" or complete "desktops." The philosophy of TAPESTRY is to connect the everyday computing resources used by participants in their everyday work (e.g., laptops, desktop machines, specialist data clusters) to the shared workspace allowing users to work with their existing applications and move fluidly from their individual work (i-work) to collaborative work scenarios (we-work) and back. ${ }^{4}$ As Huang et al. [2006] have demonstrated with NASA's MERBoard, people will reject the technology

\footnotetext{
${ }^{4}$ One of the continued themes throughout this work is that work practices take place within an ecology of artefacts and spaces that people move through. In thinking about the design of blended interaction spaces, it was our explicit intention not simply to design a circumscribed system but one that would sit well within the
} 

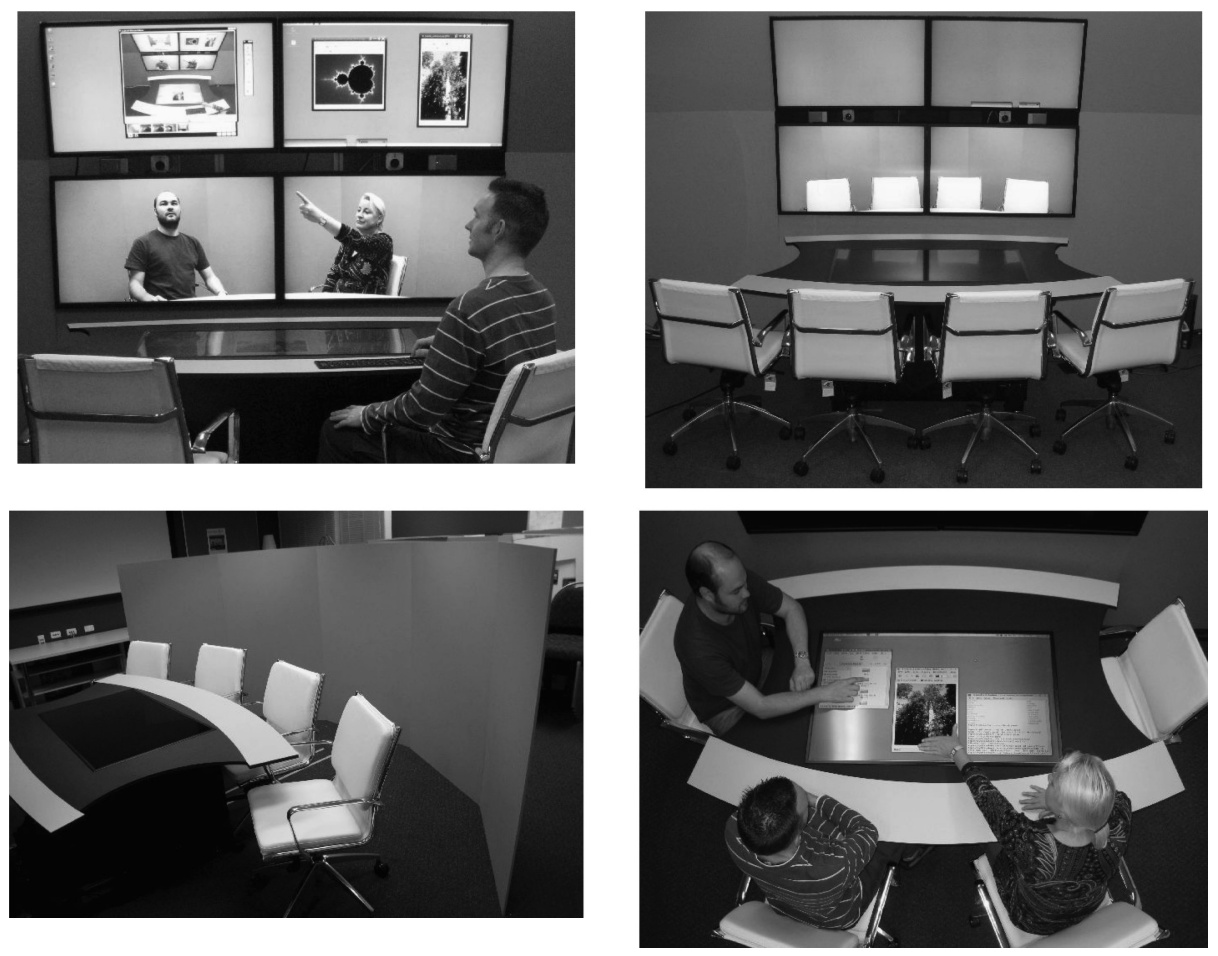

Fig. 2. The BISi set-up.

in spite of its interactional affordances if it is cumbersome to get information and applications to and from the system.

The TAPESTRY system combines a lightweight and extensible distributed system infrastructure for synchronous collaboration featuring wide-area federation and uniform service modeling (Livespaces [Phillips 2008]), OpenGL-based desktop, and advanced application sharing capable of efficient rendering of data- and graphics-intensive applications (Virtual Terminal [Jiang et al. 2007]). Applications and files on the TAPESTRY then essentially run from their source machines. TAPESTRY also incorporates the Multi-Pointer X server (MPX ${ }^{5}$ ), a multi-input-device-capable windowing system that enables multipoint interaction for new and legacy applications (within the particular architectural constraints of the legacy applications). As such, TAPESTRY enables multiple applications, windows, and desktops from different source machines to be viewed and interacted with concurrently on the same interactive surface.

\subsection{BISi Set-Up}

The physical set-up for BISi can be seen in Figures 2 and 3. A $2 \times 2$ array of LCD displays occupies the front wall. Each of these displays is $102.7 \mathrm{~cm} \times 63.5 \mathrm{~cm}$ operating at a resolution of $1920 \times 1080$. As with the Halo system, the lower displays are used for presenting video conferencing streams from the remote sites, again positioned at the appropriate height to enable across-the-table eye-gaze. Above the cameras is the second

broader ecology of the workspaces and enable fluid movement to and from that space. The ability to transfer digital as well as physical artefacts between these spaces formed a strong part of the design focus.

${ }^{5} \mathrm{http}: / /$ wearables.unisa.edu.au/mpx/?q=mpx 


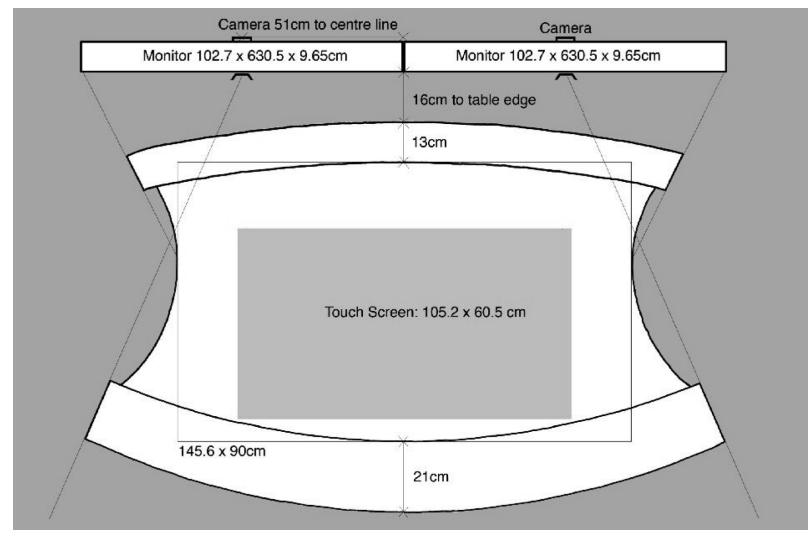

Fig. 3. Schematic overview of the BISi setup.

row of displays that are used to display the TAPESTRY collaborative workspace surface continuously across both displays. The top edges of these displays are tilted 18 degrees away from the front wall. The LCD panels are surrounded by wall-panels mounted flush with the front edge of the displays (the color of the walls is a continuation of the color of the TAPESTRY surface and the background of the video displays) creating the effect of the displays being a continuation of the wall surface. In-between the upper and lower displays are two high-definition video cameras providing parallel video streams to the two corresponding displays of the far end set-up. These are positioned at $51 \mathrm{~cm}$ to the right and left of the vertical center line between the two displays respectively. The system also incorporates a multitouch interactive horizontal surface for interacting with information in the shared TAPESTRY environment. The table is set at a standard conference table height of $72.5 \mathrm{~cm}$. Measuring from the center line of the vertical display grid, the rear end of the table is positioned $16 \mathrm{~cm}$ from the vertical displays. Continuing along this central axis of the table, the frontmost point of the curved edge is positioned $140 \mathrm{~cm}$ away from the vertical displays. The multitouch surface within the table frame is a $1920 \times 1080$ high-definition display measuring $105.2 \mathrm{~cm}$ by $60.5 \mathrm{~cm}$ (46" diagonal) and is capable of tracking multiple fingers and hands from multiple users.

From the set-up depicted in Figures 2 and 3, we can see how the system draws on the blended spaces design philosophy in terms of display arrangements, front wall design, table positioning and geometry, etc. But there are particular design features, challenges, issues, and compromises arising from the attempts to position the space for the support of smaller groups and more intense interactive collaboration tasks. These issues begin to form our agenda and understanding around Blended Interaction Spaces in a way that extends beyond the initial blended spaces philosophy highlighted through our discussion of Halo.

The first challenge with this part of the design space concerned the physical dimensions of the space. For this type of collaboration, we were dealing with smaller group sizes as well as more intense discussion around shared data artefacts. In accommodating this group size and type of discussion, the geometries of the space needed to be smaller than Halo with less interpersonal distance between the collaborating participants than was seen in Halo. While still in the Hall's [1966] range of interpersonal social distance $(1.2 \mathrm{~m}-3.6 \mathrm{~m})$, appropriate for work-related meetings, the BISi system aimed to work at the more intimate end $(1.2 \mathrm{~m})$ of this interpersonal social distance range, in a way that would enable the shared visual and physical access to the tabletop-based 

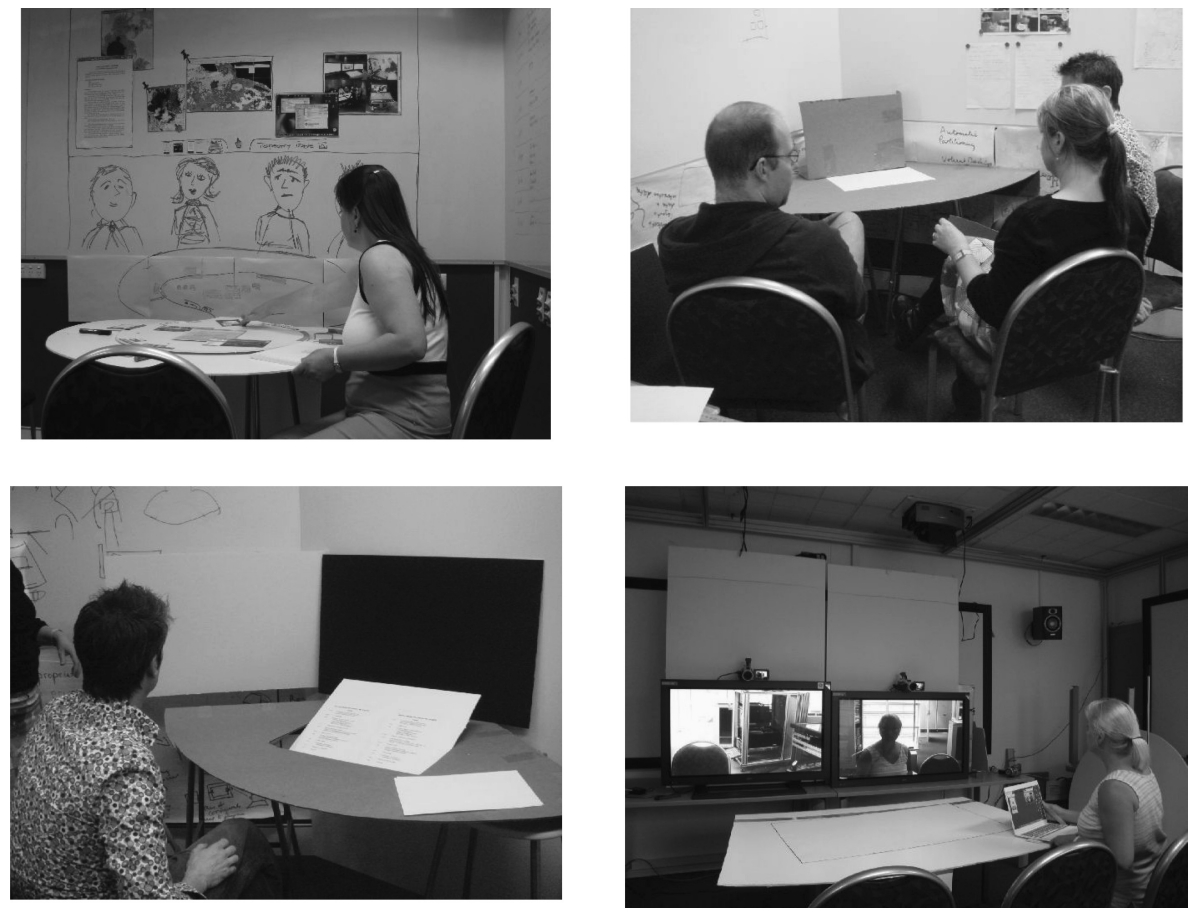

Fig. 4. Iterations of full-scale mockups of Blended Interaction Spaces.

O-space [Kendon 1990] between the collaborating parties. Table shape, and size are key issues here that present some initial challenges in the development of such spaces. While early paper-based sketching allowed exploration of initial shape concepts for the BISi system to meet these criteria, it was quickly apparent that such sketches were limited in terms of understanding of scale and proxemic arrangements of collaborators in relation to work artefacts and a sense of what these might feel like. In developing our understanding of size, shape, and positioning, then, it was important to conduct design iterations with full-scale mockups (see Figure 4). Cardboard and foam board were ideal materials here for creating different table shapes and sizes, and different workspace display configurations. These materials could be quickly reshaped and were light enough to be reconfigured in many arrangements that allowed many iterations to be experienced. Experiencing these early iterations was an important component in understanding relationships and trade-offs between factors such as physical proximity from other people, proximity from information and displays, sense of reach, and sense of object manipulation. For example, in one iteration where a mockup semicircular table design was created, this seemed to provide appropriate interpersonal distances and shared reach access to tabletop documents for local collaborators. However, it was also apparent that this design positioned certain participants uncomfortably close to mockup video displays; this lead to exploration of other shapes and configurations to avoid this consequence.

The challenges of these interdependent factors in developing these kinds of spaces is made further apparent with the introduction of video cameras and displays. Achieving the appropriate size representation of the remote parties at appropriate interpersonal distances and visibility of the table edge on the remote screens (for perception of continuity across the sites) is affected by table size, height, and distance from the screens 
combined with the positioning, orientation, and zoom levels for the camera set-up. These factors are massively interdependent and changes in any of them require compensation in the others. Again the low fidelity of the foam board table prototypes is important at this stage, enabling fine-grained adjustment of camera parameters in combination with adjustments in table sizes, shapes, and distances. This refinement of the set-up is necessarily a painstaking process that involves an informed experimentation with different parameter changes until the desired combination is reached. ${ }^{6}$ At the smaller distances (relative to Halo) appropriate for these group sizes and type of collaborative work, this balance of interdependencies is somewhat brittle. But there are further challenges with this balance arising from the larger range of focal planes to be accommodated due to the proxemic consequences of the interaction mechanisms in the space. With Halo, one could make the assumption that people would be positioned in the plane set by the table edge; the interaction mechanisms present in Halo do not cause people to shift from this plane. Indeed, this is one of the key features of the design in which the table creates this fixity of position. With BISi, the interactive capabilities and their proxemic consequences introduce a new set of behavioral assumptions that need to be considered. For instance, when people need to point to objects on the upper part of the table they tend to lean over, thereby moving closer to the camera. This results in certain magnification anomalies in the image as well as potential breaks in the panorama continuity. Such magnification anomalies are affected by the combined factors of camera zoom levels, focal length, and depth of field, for example being increased at high zoom levels. As such this issue needs to be compensated for in our choice of zoom and focal length as well as table dimensions and distances from the camera. So table dimensions and distances from the displays are designed in part with these factors in mind to reduce where possible the amount of leaning forward and to minimize magnification distortions through choice of lower zoom levels. ${ }^{7}$ Alternative design considerations here would be to introduce tabletop interaction mechanisms that do not encourage such physical leaning and which would allow an assumption of narrower focal planes. An example of such a technique here would be the Pantograph that provides a greater virtual reach than direct touch mechanisms employed in BISi (e.g., Nacenta et al. [2007]). ${ }^{8}$

The geometrical arrangement of information on the interactive surfaces is also a particular challenge in the context of a blended environment arranged as a distributed environment. The data screens being positioned above the video screens need to be tilted forward by an angle of 18 degrees for more comfortable viewing at these small interpersonal distances. But the particular challenge arises out of the desire to maintain the spatial coherence of pointing and eye-gaze as represented on the video screens with respect to different information sources. There are well-established differential rotation effects in $2 \mathrm{D}$ representations of $3 \mathrm{D}$ scenes for pointing and gaze, whereby orientations of gaze and pointing are increasingly misjudged with larger viewing

\footnotetext{
${ }^{6}$ The important point about these systems is that their design involves a complex series of trade-offs. Exploring these trade-offs is neither "black art" nor "exact science" but, rather, is a principled exploration within the bounds of understood socio-technical issues. One of the key aims of this article is to provide an awareness of the proxemic issues and principles within which blended interaction spaces can be designed, explored, and understood.

${ }^{7}$ There are other factors to be considered in the design of the table dimensions that will be discussed later. As such there are a complex set of trade-offs that are being balanced in the design that go beyond optimizing table design to reduce these magnification anomalies.

${ }^{8}$ The work of Nacenta et al. [2007] is an important example of a study that systematically articulates the spatial consequences of a range of different tabletop interaction techniques. This kind of study of interaction proxemics in relation to other interaction technologies will form a key part of the understanding necessary to effectively introduce interaction possibilities into new blended interaction spaces.
} 
angles away from the perpendicular (e.g., Goldstein [1987]). As distances from the screen are reduced (e.g., with the smaller interpersonal distances in BISi compared to Halo), these effects can be increased. These effects need to be compensated through use of multiple cameras and through constraints on the width of the overall system (thereby reducing viewing angle differentials). In the BISi system, a dual camera set-up was used to mitigate these effects. Attaining satisfactory levels of gaze and pointing accuracy also impacted judgments of table distance and width. Reducing table width and increasing distance from the screen can both help reducing differential viewing angles and differential rotations effects. Attempts to achieve satisfactory levels of pointing and gaze accuracy were also factors in our iterative adjustments of table dimensions and positioning distance from the screens. With these kinds of display technologies, it is not possible to remove these effects completely. In our experiences with the system, determining who is looking at who can be achieved to a satisfactory level with the BISi set-up, as with Halo. Such discrepancies in accuracy do affect the level of spatial granularity with which deictic reference can operate. For higher-level pointing tasks such as pointing to a large information object such as an onscreen window, this accuracy in our experience with the system is acceptable. For finer-grained deictic referencing requirements, the approximations are not always sufficient and better achieved by pointing and gesturing with shared cursors. However, some of these issues can be overcome with more sophisticated multiview display and camera set-ups such as in the work of Nguyen and Canny [2005].

But there are deeper levels of complexity associated with this issue. Typically in CSCW systems for remote collaboration, a key design principle for shared workspaces is based on the notion of "what you see is what I see" (WYSIWIS). Such a principle, of course, has much evidential support as a deictic conversational resource. Within a Blended Interaction Space though, if we simply present the same representation on both ends of the remote collaboration, both will see the same thing but this will not match what their perspective would be if the space's geometrical arrangement were considered. For example, if there is an information window on the leftmost edge of Room A's and Room B's display, when physically pointing on the video conference, both parties would appear to be pointing and looking in opposite directions, even though they would actually be looking at a common piece of information. With Halo, this was not so much of a problem in the chosen design. Having a single data screen placed in the center of the front wall and at a further distance from the participants all contributed to the achievement of correct gaze directionality with respect to the data display. That is, when people look at any data on the data screen in Halo they will appear to stare broadly into the middle of the room, so issues of directionality are not perceived or made visible. In BISi, the problem is exacerbated by the need for a larger information space and the use of multiple data screens at a shorter distance from the participants. This means that the angle subtended by the data displays is much wider than in the Halo room, making the directional anomalies more visible when looking at a specific place on the data screen.

There are a number of solutions to be considered here. Ideally these should adopt as much as possible a spatial reference domain where there is a match between information organization and the arrangement of the displays, as has been shown effective in other multidisplay environments (see Nacenta et al. [2009] for an overview). The use of spatial reference domains works well for collocated multidisplay environments but new challenges are introduced when trying to do this in distributed environments, in particular, those distributed environments where the representation of user actions is both through the video channel and digital representations such as pointer movement (i.e., Blended Interaction Spaces). As such, the solutions available to us are not without some compromise along this dimension. For example, it is possible to adopt various 
mirror arrangements (refer to Ishii and Koboyashi [1992]), whereby the screens in each room are a mirror image of those in the other room. While this solves the spatial issues it obviously leads to difficulties with the presentation of information which, if mirrored, is not readable. With this in mind one can adopt partial mirror solutions in which there is higher-level mirroring of window frames on the TAPESTRY while the information within the windows is presented in the correct orientation. But this introduces problems of cursor leaps as one moves a pointer across the TAPESTRY surface and over a window. We have tried the much simpler solution of swapping things at the screen level, so that data presented on the left-hand screen of the local room would be presented on the right-hand screen of the remote room and vice versa. This solution achieves high-level gaze and pointing directional accuracy. It also comes with some level of cursor leap when moving from one screen to another for one of the rooms participating (since the center line for one location maps to the far right or left in the other, depending on the direction the cursor is moving in). This was our chosen compromise, in the first instance, being broadly commensurate with some of the other achieved pointing accuracy levels arising from differential rotations effects. But in many ways this remains an open issue requiring more systematic research and innovation. What is important here though is the demonstration of the new interacting factors that arise when introducing new interactive workspace capabilities. We can see again the ways that the architecture, furniture, and technology arrangements (both hardware and software) are intimately intertwined with a set of interdependencies where changes in any of these components lead to consequences that need to be compensated for in the configuration of the other components.

Similar issues arise when we consider the horizontal interactive surface in the BISi set-up where there remain open questions as to how information on the horizontal surface should be presented. The arguments here are potentially at odds with the standard CSCW convention of WYSIWIS. While the WYSIWIS approach is most appropriate in situations where only virtual pointing is available, the paradigm conflicts with the desire for geometric consistency with respect to pointing and gaze portrayed through the video representation. In this sense we potentially reduce the sensation of sitting on the opposite side of the table.

Again there are a number of approaches to take here. One is to adopt some of the methods outlined earlier for information presented on the vertical displays. A second approach is to present information on the remote table from the perspective of someone sitting at the opposite side of the table. This, of course, may lead to difficulties with certain pieces of information being upside down. But the arguments here are that the control and presentation of information would be socially mediated through rotation, orientation, and other forms of micromobility [Heath and Luff 2000; Kruger et al. 2003] in the same way that paper and other artefacts are oriented in collocated physical settings. This approach is designed to facilitate the sensation of remote parties being on opposite sides of the physical table. It also aims to enable the portrayal of social meaning and coordination control through the actions on the digital artefacts of the surface, for example, using orientation of a document to control privacy or to signal an invite to look at the document (e.g., by rotating the document towards the remote participants). A third approach is to treat the local and remote tabletop surfaces as a continuous space extending through the plane of the video wall. In this respect, the local and remote parties will see a different part of the information surface but can "push" information from their side of the tabletop "through" the plane of the video wall to appear on the remote surface. This respects some of the physical geometries of the physical and information space, but potentially conflicts with others (for example, the information space may extend a little behind where the remote participants are perceived to be sitting). 
The TAPESTRY system can be configured in different ways according to these different approaches. Again the intent here is not to propose the single perfect solution but rather to highlight the key issues, challenges, and potential trade-offs arising from these different approaches to introducing interactive surfaces and artefacts in geometrically appropriate Blended Interaction Spaces. Configuring the system in different ways provides us with the basis for more systematic research enquiry into the properties of these different approaches.

An area where the spatial consequences of our interactive design choices are further apparent is in the use of the multitouch table and MPX system as a way of providing multipoint capabilities in the system. From a spatial point of view, one of the things this brings to the system is multiple access points [Hornecker and Buur 2006; Rogers and Lindley 2004] whereby all the participants can concurrently interact with the system. ${ }^{9}$ These authors have demonstrated the important properties of multiple access points in terms of collaboration dynamics. The particular concern of importance to us in the design of the BISi system is that it allows interaction by all present in the meeting from wherever they are sitting. As we discussed earlier with respect to the Halo system, one of the key things is for there to be a strong coupling of participant positions with respect to the camera and display configuration in order to achieve the desired blended effects, this being done through particular characteristics of the furniture such as table size, shape, positioning, and the table legs. But within Halo, there is only single point access to the data presented on the screen being controlled through the laptop of the person presenting the information. If another participant wanted to interact with the data on the display she would need to get up and move to the location of the laptop. In doing this, she would break the carefully crafted coupling of her position with the camera and display set-up. In the BISi system, we can see then that the provision of multiple access points available from the users' seating position enables the close coupling between participant position and camera positions to be maintained during the course of any interaction.

A related point here concerns the use of laptops within the BISi system. As we have discussed, BISi was designed to allow participants to connect their laptops to the system. This again serves a purpose of providing multiple access points to the system from wherever people are sitting. Support for this activity goes beyond just the connectivity of these devices. There are additional physical requirements necessary to support this activity. The table rim was designed explicitly with a visual and textural delineation of bench space to enable the comfortable placement of these laptops (among other artefacts such as paper documents and input devices) on the surface in the personal space of the seated participants. It was designed as a compromise between the need to have space for these items while not interfering with the ability to reach the horizontal touch screen. A distance of $21 \mathrm{~cm}$, the width of small laptops, and A4 documents in landscape orientation was found to be suitable, as illustrated in Figure 5.

\section{DISCUSSION}

Our concerns in this article have been to articulate the key features and theoretical foundations of what we call Blended Interaction Spaces. These are distributed collaboration environments that attempt to faithfully incorporate geometrical properties and configuration of space, which have been shown significant in the organization of communication behavior in physical space. In developing these arguments, we have

\footnotetext{
${ }^{9}$ There are obvious inherent constraints of legacy applications here that are designed for single person interaction. Multiple cursors can enter into these applications at the same time and point but there is a need for "floor control" mechanisms to manage input from these multiple pointers in a way compatible with the input capabilities of the legacy applications.
} 


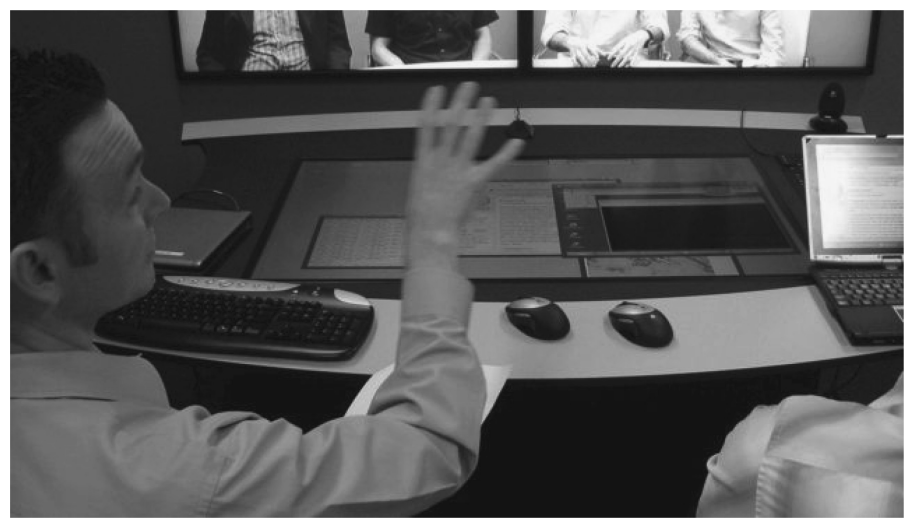

Fig. 5. Table rim in BISi designed to accommodate keyboards, pointing devices, as well as laptops that people might need to bring into the collaboration without interfering with the horizontal touch surface.

drawn extensively on a long tradition of literature within media space research and work examining the relationship between spatiality and human interaction. Of particular significance here have been the theoretical framework of embodied interaction and theories of the spatial organization of behavior such as Hall's [1966] proxemics and Kendon's [1990] interactional spaces. These understandings of the spatial organization of behavior provide important analytical lenses through which developments in media space research and design have and can continue to be understood. More specifically, they provide the resources with which we can think about new kinds of media space environments, of concern in this article, that explicitly address these spatial concerns in their design. In order to more concretely articulate the design ideas, principles, and issues involved, the article takes as a launch point a discussion of Gorzynski's [2009] original concept of Blended Spaces. Our approach here has been to further elucidate the ideas concerned through an examination of a canonical example of a Blended Space, namely HP's Halo collaboration environment. This has allowed us to explore some of the key design features that contribute to the perception of a shared spatial geometry between users working across distributed environments. Our concerns here are not simply with the specifics of the Halo environment, but more broadly how they help communicate some of the more general design considerations and ways of thinking that need to be applied in developing different types of Blended Spaces.

It is our thinking about other types of Blended Spaces that requires us to extend the original notion to encompass Blended Interaction Spaces: distributed environments that encompass possibilities for richer collaboration over distributed interactive workspaces in which the communication is an integral part of a collaborative analysis and interpretation of presented information; where the group needs to gesture, point, interact with and manipulate presented information in the context of their ongoing discussion. While such environments in some sense form part of the larger set of Blended Spaces, there are important reasons why such a conceptual extension is necessary and valuable. By introducing interactive workspace capabilities within such environments, we fundamentally change some of the behavioral and spatial assumptions that can be relied upon in the creation of a perception of shared spatial geometries. Through making the extension to Blended Interaction Spaces, we specifically draw attention to the spatial consequences of the interactive workspaces. Again, as with the Halo discussion, our approach in articulating these concerns is through an examination of a canonical example of a Blended Interaction Space called BISi. And again, our aims in articulating these design details lie in more than just the specifics of the BISi system itself. Our 
intent through this illustration is to highlight some of the key design considerations, issues, and a more general way of thinking that is pertinent to the design of other systems of this genre. With other systems, some of the specifics will change, but the overarching design philosophy will remain the same.

In presenting this discussion, there are a number of key issues that the work has highlighted. First is the important notion of interaction proxemics. Drawing on Hall's [1966] original concept of proxemics, this notion makes particular reference to the spatial consequences of different interaction mechanisms in terms of the way they position people with respect to information resources and in terms of how they dynamically configure people with respect to each other during the ongoing course of collaboration. What we are arguing for, then, is for greater understanding and reflection on the spatial consequences of particular interaction mechanisms so that they can be combined appropriately with architectural and furniture elements with particular effect. Understanding the interaction proxemics of particular interaction mechanisms forms an essential part of the spatial assumptions that need to be worked with in the creation of a blended environment. So in the same way that table design allows embodiment of assumptions about spatial positioning of people in the environment, we need to do something similar with the interaction mechanisms. We are beginning to see some informative work to this end, for example, in the domain of tabletop interaction mechanisms and territoriality (e.g., Nacenta et al. [2007]). While this work has focused its attention on collocated collaboration, it is nevertheless informative to our more specific spatial concerns with distributed collaboration environments. What we would argue is that this kind of work needs to be extended to a broader range of interaction mechanisms and configurations that might usefully be incorporated within other Blended Interaction Spaces (e.g., touchless gesture-based interaction).

A second set of issues arising out of the move from Blended Spaces to Blended Interaction Spaces comes from the spatial qualities of the data space and in particular how to map this onto the geometric properties of the space envisioned. In our discussion of BISi we have seen ways this can be informed from other work in multidisplay environments but also the additional complexities of trying to do this across distributed environments. What we have also seen is that the attempts to pursue spatial continuity across the distributed boundary can potentially lead to design conflicts with well-established design philosophies in CSCW such as WYSIWIS. In developing the Blended Interaction Space paradigm, such potential conflicts need to be the subject of a systematic research effort to more fully understand their implications for distributed collaborative practices.

What we also hope to have highlighted in our arguments about Blended Interaction Space systems is an attention not simply to the details of technology design but also to the details of architectural and furniture elements. In presenting our discussion of Halo and BISi, we have shown how these components are tightly coupled together in mutually dependent relationships and that adjustment in one component intimately affects our experience with other components. By paying attention to all these different components together, it is possible to exploit these interdependencies to good effect. For example, we have seen the use of furniture design to embody assumptions in the environment about the positioning of people. This information is then something that can be used in configuration and placement of cameras and in configuration and placement of displays. We have also seen examples where architectural design has been used to compensate for certain aspects of the technology such as image distortions. An example here is the lack of features on the walls, avoiding horizontal and vertical lines that make salient any distortions. As well as thinking about this issue in relation to Blended Interaction Spaces, we believe that these considerations of architectural, technological, and furniture relationships can be applied more generally to CSCW 
design in collocated situations, that is, applying attention not just to the technological but also giving consideration to the technological within the context of architectural and furniture elements. By attending to these other elements, it is possible to change people's spatial relationships with the technological. Hall's [1966] proxemics are again informative here in his articulation of how architecture and furniture can affect the nature of interpersonal interactions and social action.

Following on from this in blended interaction space philosophy is the argument, drawn from traditional workplace design literature, for a varied set of spaces, each designed specifically to afford different aspects of individual and collaborative work practice. That is, in everyday work practices, people work in an ecology of interlinked spaces moving between them and exploiting their respective affordances for the unfolding demands of work. While we have illustrated the concept of Blended Interaction Spaces through the discussion of the BISi system, this system is really a starting point in thinking about the development of a larger ecology of these spaces. This is an important reason why our concerns go beyond the specifics of the Halo and BISi systems to encourage thinking about this broader potential ecology of Blended Interaction Spaces. Each of these points in the design space can draw inspiration from the varied physical workspaces that make up the spatial ecology of the modern office place. This approach attempts to deal with the varied nature of work practices through a combined system of purpose-designed spaces as opposed to designing single general-purpose spaces or technologies that accommodate varied practices and circumstances through configurability and tailorability. In taking this system-of-spaces approach, Blended Interaction Spaces trades off the values of purpose-built design with the values of flexibility and extendibility (e.g., extending to more and more nodes than one gets, for example, with Access Grid-type technology). In this respect, we can draw some parallels between the appliance (purpose built) and convergence (general purpose) debate discussed by authors such as Norman [1998] with Blended Interaction Spaces being at the appliance end of the design approach : well-designed spaces with very particular purpose. As with the appliance/convergence model these devices can coexist (refer to Dourish [2001]). In advocating the importance of Blended Spaces, our intent is not that these should be at the expense of other more general-purpose video-mediated communication tools. Rather, it is envisioned that these different kinds of systems will coexist according to the particular values they have acquired.

In presenting the ideas here, and in particular the emphasis on providing shared spatial geometries across distributed environments, there is some concern that the Blended Interaction Space approach be viewed simply as an uncritical and blind pursuit of the "being there" experience. However, just because we are highlighting spatial characteristics and the importance of physical space design does not mean that we are advocating what Fitzpatrick [2003] and others such as Harrison and Dourish [1996] might characterize as a "space-based" approach to the design of these systems. Rather our concerns are much more in line with the "place-based" approach [Fitzpatrick 2003; Harrison and Dourish 1996] to the design of collaboration systems; that is, the design and use of space for place-making where meaning making takes place through the actions in the space [Fitzpatrick 2003]. With this in mind, our reasons for trying to maintain spatial geometries in the design of distributed environments can be grounded in the ideas of embodied action. From these it is argued that the representation of geometrically accurate spatial continuity across distributed spaces can facilitate visible access to and understanding of the gestures, actions, and orientations of others in relation to the spatial environment and understanding of how our own actions, gestures, and orientations appear to others in relation to the environment. Having a shared spatial geometry can help overcome negative consequences arising from orientation and perspective disparities that can affect in-the-moment coordination of conversational mechanics. Through 
this, it is possible to overcome some of the difficulties associated with the fractured and disembodied experiences with some early video-mediated communication and have a space that affords "place-making" through the more embodied experience.

When making these arguments, it is important to treat them with an appropriate perspective. As we discussed earlier, the claims being made are not about the necessity or sufficiency of shared spatial geometries as a basis for successful collaboration. The numerous examples of distributed collaboration technologies that are usefully incorporated into people's lives, making no attempt to represent spatial geometries, are testament to this (telephone, instant messaging, etc.). So while people can and do communicate without coherently represented spatial geometries, our arguments are that the provision of shared spatial geometries can facilitate and make easier aspects of communication, coordination, and collaboration. As Healey and Battersby [2009] argue, people make use of them when they are available, offloading the mental demands of conversational and gestural reference to the spatial geometries of physical and interactional space. The facilitation effects of these cues are particularly relevant where visual communication channels are used to provide spatial reference points and which are "assumed" to be congruous but where orientation disparities lead to a confusing incongruity, such as in video-mediated communication.

\section{CONCLUSION}

In this article, we have presented an analysis of the concept of Blended Interaction Spaces. Our chosen approach here has been to combine the theoretical underpinnings of the concept with important design issues illustrated through analysis of concrete system examples. In adopting this approach, our aims go beyond the specifics of the systems explored in the article. Rather, our intention has been to provide some of the important analytic foundations through which such systems can be conceived and studied in a more principled way.

Out of this analytic foundation there arises a broad set of interesting empirical issues and questions that can form part of a larger research agenda. These relate to a number of different areas. The first concerns the impact of these environments and proxemic concerns on the mechanical aspects of communication and collaboration. As with other media space research, these concerns apply not simply to performance outcome measures but also to characterization of process of communication and collaboration. That is, these systems can be evaluated in terms of particular spatial configurations that result in more effective decision-making or more effective collaborative interpretations. They can also be measured in terms of the ways that they change communication and collaboration style, for example, do they result in different utterance or turn taking patterns, or different patterns of gesture? As well as these quantitative analyses, it is important to complement this with more detailed qualitative interaction analysis of these kinds of systems such as those applied by Heath and Luff [1991, 1992, 2000] in earlier media space research. In the same way that they highlighted some of the problems of media space asymmetries, these kinds of analyses can help relate particular interaction behaviors and utterances to the geometrically faithful representations of Blended Interaction Spaces. This kind of research into the mechanical aspects of communication and collaboration applies not just to the specific Halo and BISi systems but also to a broader ecology of Blended Interaction Spaces with different proxemic configurations.

A second area of empirical interest arising from the discussion here relates to the specific question of interaction proxemics. The systems discussed here highlighted issues related to the particular interaction mechanisms and configurations used in their design. This points to a larger agenda of understanding the spatial consequences of existing input technologies and interaction techniques. Experimental studies around this issue can, of course, utilize spatial tracking technologies of bodies and body parts, as well 
as input logging technologies to create important data components in the visualization and systematic analyses of these spatial consequences. However, the research agenda here is more complicated than simply taking a particular interaction technique and mapping out the particular spatial behaviors around it. As we have argued earlier, these spatial consequences will also be shaped by the presence of other competing influences on spatial behavior within blended space environments. For example, the need to be positioned on camera, or the presence of other interaction mechanisms are likely to interact with the basic interaction proxemics of a particular input device. As such, in conducting experimental analyses of interaction proxemics, it will be important not just to examine interaction mechanisms in isolation but within the context of other artefacts and issues with distributed collaboration and Blended Interaction Spaces.

A final area of empirical work, drawing on arguments made by Schmidt [2009], concerns the less mechanical aspects of communication and collaboration. The current presentation of Blended Interaction Spaces put forward in this article has focused on the mechanical aspects of collaboration and conversation and how this is facilitated by particular material properties and design characteristics of these spaces. This focus has enabled a level of clarity in the presentation of the arguments but it is important to recognize this as just the initial part of the understanding of these kinds of Blended Interaction Spaces. Missing from this more mechanical emphasis are any details of actual work practice and behaviors within particular organizational contexts. There is a need then for an empirical assessment of Blended Space systems, such as Halo, BISi, and others, within real-world organizational contexts. Rather than focusing on the mechanical properties of communication, such an empirical agenda will aim to understand how and why particular details and characteristics of work practice within particular organizational settings relate to the geometrical properties of these distributed spaces. Through more ethnographic enquiry into these work practices, it should be possible to articulate further reasons why, in particular organizational contexts, people do and don't orient to common spatial references in the shaping of their work practices and the ways embodied interaction within a range of organizationally situated Blended Interaction Spaces creates meaning and the production of "place."

\section{ACKNOWLEDGMENTS}

The ideas developed here have been informed and influenced by a number of key people. We would like to thank the HP Halo team, in particular, Mike Derocher, Mark Gorzynski, and April Slayden Mitchell, who formulated the original Blended Space concept and, through many helpful discussions, informed some of the ideas articulated in this article. We would like to thank too those at Steelcase Workplace Futures, in particular Terry West and Mark Bologa, for their insights into the relationship between architecture, furniture, and technology that have been an important inspiration for this work. Thanks also to all the members of the HxI collaboration between CSIRO, DSTO, and NICTA in Australia who contributed to the development of the BISi system. Finally, many thanks to Richard Harper and all the reviewers for their critical insights and comments on earlier drafts of this article.

\section{REFERENCES}

Becker, F. And Steele, F. 1995. Workplace by Design: Mapping the High Performance Workscape. Jossey-Bass, San Francisco.

BLy, S. 1988. A use of drawing surfaces in different collaborative settings. In Proceedings of the Conference on Computer Supported Cooperative Work (CSCW'88). 250-256.

Bly, S. And Minneman, S. 1990. Commune: A shared drawing surface. In Proceedings of the 5th Conference on Office Information Systems. 184-192.

Broughton, B., PaAy, J., KJeldskov, J., O’Hara, K., Li, J., Phillips, M., and Rittenbruch, M. 2009. Being here: Designing for distributed hands-on collaboration in blended interaction spaces. In Proceedings of the Australian Conference on Computer-Human Interaction (OzCHI'09). 73-80.

Buxton, W., Sellen, A., And Sheasby, M. 1997. Interfaces for multiparty videoconferencing. In Video Mediated Communication, K. Finn et al. Eds., Erlbaum, Hillsdale, NJ, 385-400. 
Buxton, W. 2009. Mediaspace-Meaningspace-Meetingspace. In Media Space: 20+ Years of Mediated Life, S. Harrison Ed., Springer, London, 217-231.

Covi, L. M., Olson, J. S., AND Rocco, E. 1998. A room of your own: What do we learn about support of teamwork from assessing teams in dedicated project rooms? In Cooperative Buildings, N. Streitz et al. Eds., Springer, Amsterdam, 53-65.

DourISH, P. 2001. Where the Action Is: The Foundations of Embodied Interaction. MIT Press, Cambridge, MA.

Dourish, P. 2006. Re-Space-ing place: Place and space ten years on. In Proceedings of the ACM Conference on Computer-Supported Cooperative Work (CSCW'06). 299-308.

Dourish, P., Adler, A., Bellotti, V., ANd Henderson, A. 1996. Your place or mine? Learning from long-term use of audio-video communication. Comput.-Support. Coop. Work 5, 1, 33-62.

Duffy, F. 1997. The New Office, Conran Octopus, London.

Finn, K., Sellen, A., AND Wilbur, S. 1997. Video-Mediated Communication. Erlbaum, Hillsdale, NJ.

FitzPatrick, G. 2003. The Locales Framework: Understanding and Designing for Wicked Problems. Kluwer Academic Publishers.

Gaver, W., Sellen, A., Heath, C., ANd Luff, P. 1993. One is not enough: Multiple views in a media space. In Proceedings of the ACM Conference on Human Factors in Computing Systems (INTERCHI'93). 335-341.

GolDSTEIN, E. B. 1987. Spatial layout, orientation relative to the observer, and perceived projection in pictures viewed at an angle. J. Experiment. Psychol. Hum. Percept. Perform. 13, 2, 256-266.

Gorzynski, M., Derocher, M., and Slayden Mitchell, A. 2009. The Halo B2B studio. In Media Space 20+ Years of Mediated Life, S. Harrison Ed., Springer, London.

HaLl, E. T. 1966. The Hidden Dimension. Doubleday, New York.

HARPER, R. H. R. 1998. Inside the IMF: An Ethnography of Documents, Technology and Organizational Action. Academic Press, London.

HarRison, S. 2009. Media Space: 20+ Years of Mediated Life. Springer, London.

HARRISON, S. AND DouRISH, P. 1996. Re-Place-ing space: The roles of place and space in collaborative systems. In Proceedings of the ACM Conference on Computer-Supported Cooperative Work (CSCW'96). ACM Press, New York, 67-76.

Healey, P. H. and Battersby, S. A. 2009. The interactional geometry of a three-way conversation. In Proceedings of the $31^{\text {st }}$ Annual Conference of the Cognitive Science Society. 785-790.

HeAth, C. AND LufF, P. 1991. Disembodied conduct: Communication through video in a multi-media environment. In Proceedings of the ACM SIGCHI Conference on Human Factors in Computing Systems (CHI '91). 99-103.

Heath, C. ANd Luff, P. 1992. Media space and communicative asymmetries: Preliminary observations of video-mediated interaction. Hum.-Comput. Interact. 7, 315-346.

Heath, C. And Luff, P. 2000. Technology in Action. Cambridge University Press, Cambridge, UK.

Hirsh, S., Sellen, A., AND Brokopp, N. 2005. Why HP people do and don't use videoconferencing systems. HP Tech. rep. HPL-2004-140(R.1).

Hornecker, E. AND BuUR, J. 2006. Getting a grip on tangible interaction: A framework on physical space and social interaction. In Proceedings of the ACM SIGCHI Conference on Human Factors in Computing Systems (CHI'06). ACM Press, New York, 437-446.

Hornecker, E., Marshall, P., Dalton, N. S., and Rogers, Y. 2008. Collaboration and interference: Awareness with mice or touch input. In Proceedings of the ACM Conference on Computer Supported Cooperative Work (CSCW'08). ACM Press, New York, 167-176.

Huang, E. M., Mynatt, E. D., And Trimble, J. P. 2006. Displays in the wild: Understanding the dynamics and evolution of a display ecology. In Proceedings of the Pervasive'06 Conference.

Hutchins, E. 1995. Cognition in the Wild. The MIT Press, Cambridge, MA.

Ishit, H. AND Kobayashi, M. 1992. ClearBoard: A seamless medium for shared drawing and conversation with eye contact. In Proceedings of the ACM SIGCHI Conference on Human Factors in Computing Systems (CHI'92). ACM Press, New York, 525-532.

Jiang, H., Wigdor, D., Forlines, C., And Shen, C. 2008. System design for the WeSpace: Linking personal devices to a table-centered multi-user, multi-surface environment. In Proceedings of the Tabletop'08 Conference.

Jiang, L., Krumm-Heller, A., ANd Mueller-Tomfelde, C. 2007. The virtual terminal a cross platform and high performance remote desktop sharing program. In Proceedings of the 4th CSIRO ICT Centre Conference'07.

Johanson, B., Fox, A., AND Winograd, T. 2002. The Stanford iroom and interactive workspaces project. In Proceedings of the IEEE Pervasive Computing Conference. 67-75. 
Kendon, A. 1990. Spatial organization in social encounters: The F-formation system. In Conducting Interaction: Patterns of Behavior in Focused Encounters, A. Kendon Ed., Cambridge University Press, 209-237.

KIRSH, D. 1995. The intelligent use of space. Artif. Intell. 73, 1-2, 31-68.

Kruger, R., Carpendale, S., Scott, S. D., and Greenberg, S. 2003. How people use orientation on tables: Comprehension, coordination and communication. In Proceedings of the GROUP'03 Conference. ACM Press, New York, 369-378.

Laing, A., Duffy, F., Jaunzens, D., AND Willis, S. 1998. New Environments for Working: The Re-Design of Offices and Environmental Systems for New Ways of Working. Construction Research Communications.

LARKIN, J. H. 1989. Display-Based problem solving. In Complex Information Processing: The Impact of Herbert A. Simon, D. Klahr and K. Kotovsky, Eds., Erlbaum, Hillsdale, NJ.

Mantei, M., Baecker, R., Sellen, A., Buxton, W., Milligan, T., and Wellman, B. 1991. Experiences in the use of a media space. In Proceedings of the ACM Conference on Human Factors in Software (CHI'91). 203-208.

Merleau-Ponty, M 1962. Phenomenology of Perception. Routledge, UK.

Merleau-Ponty, M. 1968. The intertwining-The chiasm. In The Visible and the Invisible. Northwestern University Press, Chicago, Illinios, ILL.

Moran, T., Saund, E., Van Melle, W., Gujar A., Fishinin, K., and Harrison, B. 1999. Design and technology for Collaborage: Collaborative collages of information on physical walls. In Proceedings of the 12th Annual ACM Symposium on User Interface Software and Technology. 197-206.

Nacenta, M. A., Gutwin, C., Aliakseyeu, D., and Subramanian, S. 2009. There and back again: Cross-Display object movement in multi-display environments. Hum.-Comput. Interact. 24, 1, 170-229.

Nacenta, M. A., Pinelle, D., Stuckel, D., And Gutwin, C. 2007. the effects of interaction technique on coordination in tabletop groupware. In Proceedings of the Graphics Interface Conference (GI'07). ACM Press, New York, 191-198.

NGuyen, D. And Canny, J. 2005. MultiView: Spatially faithful group video conferencing. In Proceedings of the ACM SIGCHI Conference on Human Factors in Computing Systems (CHI'05). ACM Press, New York, 799-808.

NGuYen, D. And Canny, J. 2009. More than face-to-face: Empathy effects of video framing. In Proceedings of the ACM SIGCHI Conference on Human Factors in Computing Systems (CHI'09). ACM Press, New York, 423-432.

Noll, A. 1992. Anatomy of a failure: Picturephone revisited. Telecomm. Policy 16, 307-316.

Norman, D. 1998. The Invisible Computer: Why Good Products Can Fail, The Personal Computer Is So Complex, and Information Appliances Are the Solution. MIT Press, Cambridge, MA.

O’Connaill, B., Whittaker, S., ANd Wilbur, S. 1993. Conversations over video conferences: An evaluation of video mediated interaction. Hum.-Comput. Interact. 8, 389-428.

Olson, G. M. AND Olson, J. S. 2000. Distance matters. Hum.-Comput. Interact. 15, 2-3, 139-178.

Olson, J. S., Olson, G. M., AND MeAdER, D. 1997. Face-to-Face group work compared to remote group work with and without video. In Video Mediated Communication, K. Finn et al. Eds., Lawrence Erlbaum Associates, Hillsdale, NJ.

Okada, K., Maeda, F., IchiKawaA, Y., ANd Matsushita, Y. 1994. Multiparty videoconferencing at virtual social distance: MAJIC design. In Proceedings of the ACM Conference on Computer Supported Cooperative Work (CSCW'94). 385-393.

OzYUREK, A. 2000. The in?uence of addressee location on spatial language and representational gestures of direction. In Language and Gesture, D. McNeil Ed., Cambridge University Press, 64-83.

OzyuREK, A. 2002. Do speakers design their co-speech gestures for their addresees? The effects of addressee location on representational gestures. J. Memory Lang. 46, 688-704.

Phillips, M. 2008. Livespaces technical overview. Tech. rep. DSTO-TR-2188, Defence Science and Technology Organisation.

Robertson, T. 1997. Cooperative work and lived cognition: A taxonomy of embodied actions. In Proceedings of the European Conference on Computer Supported Cooperative Work (ECSCW'97). 205-220.

Rogers, Y. AND BellotTi, V. 1997. From Web press to Web pressure: Multimedia representations and multimedia publishing. In Proceedings of the ACM SIGCHI Conference on Human Factors in Computing Systems (CHI'97). ACM Press, New York, 279-286.

Rogers, Y. AND LindLey, S. 2004. Collaborating around vertical and horizontal displays: Which way is best? Interact. Comput.16, 1133-1152.

Rogers, Y., Lim, Y.-K., Hazlewood, W., and Marshall, P. 2009. Equal opportunities: Do shareable interfaces promote more group participation than single user displays? Hum.-Comput. Interact. 24, 2, 79-116. 
Russell, D. AND SuE, A. 2003. Large interactive public displays: Use patterns, support patterns, community patterns. In Public and Situated Displays: Social and Interactional Aspects of Shared Display Technologies, K. O'Hara et al. Eds., Kluwer Academic Publishers, London.

Schmid, K. 2009. Divided by a common acronym: On the fragmentation of CSCW. In Proceedings of the European Conference on Computer Supported Cooperative Work (ECSCW'09).

SELLEN, A. J. 1992. Speech patterns in video mediated conversations. In Proceedings of the ACM SIGCHI Conference on Human Factors in Computing Systems (CHI'92). ACM Press, New York, 49-59.

SELLEN, A. J. 1995. Remote conversations: The effects of mediating talk with technology. Hum.-Comput. Interact. 10, 4, 401-444.

Sellen, A. J., Buxton, W., AND ARnotT, J. 1992. Using spatial cues to improve videoconferencing. In Proceedings of the ACM SIGCHI Conference on Human Factors in Computing Systems (CHI'92). 651-652. (Videotape in CHI'92 Video Proceedings.)

Sellen, A. J. ANd HaRPer, R. H. R. 1997. Video in support of organisational talk. In Video-Mediated Communication, K. Finn et al. Eds., Erlbaum, Hillsdale, NJ, 225-243.

Sellen A. J. And Harper, R. H. R. 2000. The Myth of the Paperless Office. MIT Press, Cambridge, MA.

Short, J., Williams, E., AND Christie, B. 1976. The Social Psychology of Telecommunications. Wiley, London.

Sommer, R. 1969. Personal Space. Prentice-Hall, Englewood Cliffs, NJ.

Sommer, R. ANd Ross, H. 1958. Social interaction on a geriatric ward. Int. J. Social Psychol. 4, 123-133.

SPINELLI, G. 2003. Socially distributed cognition: Computational space and collaborative artefacts for the workspace. Ph.D. thesis, Brunel University.

SPinelLi, G. AND O'HARA, K. 2001. Observing high performance team work: How space and information artefacts structure team problem solving, communication and fluid movement from individual to collaborative work. Tech. rep., Appliance Studio, UK.

Spinelli, G., Perry, M., AND O'HarA, K. 2005. Understanding complex cognitive systems: The role of space in the organisation of collaborative work. Cogn. Technol. Work 7, 2, 111-118.

SteELCASE360. 2007. Working in four-part harmony. http://content.ll-0.com/360steelcase/June2007ReadingLayout.pdf?i=060607172333.

Steinzor, R., B. 1950. The spatial factor in face to face discussion groups. J. Abnorm. Social Psychol. 45, $552-555$.

Streitz, N. A., Geissler, J., Holmer, T., Konomi, S., Müller-Tomfelde, C., Reischl, W., Rexroth, P., Seitz, P., AND STEINMETZ, R. 1999. i-LAND: An interactive landscape for creativity and innovation. In Proceedings of the ACM SIGCHI Conference on Human Factors in Computing Systems (CHI'99). ACM Press, New York, 120-127.

Streitz, N. A., ReXroth, P., AND Holmer, T. 1997. Does roomware matter? Investigating the role of personal and public information devices and their combination in meeting room collaboration. In Proceedings of the European Conference on Computer Supported Cooperative Work (ECSCW'97). 297-312.

TANG, J. AND IsAACS, E. 1993. Why do users like video? Studies of multimedia-supported collaboration. Comput. Support. Coop. Work 1, 3, 163-196.

Trimble, J., Wales, R., And Gossweiler, R. 2003. NASA's MERBoard. In Public and Situated Displays: Social and Interactional Aspects of Shared Display Technologies, K. O'Hara et al. Eds., Kluwer Academic Publishers, London.

WhitTaKer, S. 2003. Things to talk about when talking about things. Hum.-Comput. Interact. 18, 149-170.

WhitTaker, S. AND Schwartz, H. 1995. Back to the future: Pen and paper technology supports complex group coordination. In Proceedings of the ACM SIGCHI Conference on Human Factors in Computing Systems (CHI'95). ACM Press, New York, 495-502.

Weinstein, I. M. 2005. HP Halo - Performance assessment: Analysis and opinions on capabilities, features, usability, performance, and business model.Res. rep., Wainhouse.

Wigor, D., Jiang, H., Forlines, C., Borkin, M., And Shen, C. 2009. WeSpace: The design development and deployment of a walk-up and share multi-surface visual collaboration system. In Proceedings of the ACM SIGCHI Conference on Human Factors in Computing Systems (CHI'09). ACM Press, New York, $1237-1246$

Yamashita, N., Hirata, K., Aoyagi, S., Kuzuoka, H., And Yasunori Harada, Y. 2008. Impact of seating positions on group video communication. In Proceedings of the ACM Conference on Computer Supported Cooperative Work (CSCW'08). 177-186.

Zhang, J. AND NoRman, D. A. 1994. Representations in distributed cognitive tasks. Cogn. Sci. 18, 87-122.

Received December 2009; revised September 2010; accepted October 2010 